\title{
Freshwater ecoacoustics as a tool for continuous ecosystem monitoring
}

\author{
Simon Linke ${ }^{1 *}$, Toby Gifford ${ }^{2,3}$, Camille Desjonquères ${ }^{4,5}$, Diego Tonolla $^{6}$, Thierry Aubin ${ }^{5}$, Leah Barclay ${ }^{2}$,
} Chris Karaconstantis ${ }^{1}$, Mark J Kennard ${ }^{1}$, Fanny Rybak ${ }^{5}$, and Jérôme Sueur ${ }^{4}$

Passive acoustic monitoring is gaining popularity in ecology as a practical and non-invasive approach to surveying ecosystems. This technique is increasingly being used to monitor terrestrial systems, particularly bird populations, given that it can help to track temporal dynamics of populations and ecosystem health without the need for expensive resampling. We suggest that underwater acoustic monitoring presents a viable, non-invasive, and largely unexplored approach to monitoring freshwater ecosystems, yielding information about three key ecological elements of aquatic environments - (1) fishes, (2) macroinvertebrates, and (3) physicochemical processes - as well as providing data on anthropogenic noise levels. We survey the literature on this approach, which is substantial but scattered across disciplines, and call for more cross-disciplinary work on recording and analysis techniques. We also discuss technical issues and knowledge gaps, including background noise, spatiotemporal variation, and the need for centralized reference collection repositories. These challenges need to be overcome before the full potential of passive acoustics in dynamic detection of biophysical processes can be realized and used to inform conservation practitioners and managers.

Front Ecol Environ 2018; doi: 10.1002/fee.1779

$\mathrm{C}$ hanges in freshwater ecosystems are not always easily visible, and declines in biodiversity beneath the water surface can go undetected for long periods. We argue that passive acoustic monitoring of freshwater biodiversity and ecosystem health has the potential to overcome three key

\section{In a nutshell:}

- Freshwater ecosystems are surprisingly noisy, with underwater sounds produced by aquatic plants and animals, physical processes (eg turbulent water flow), and human activities

- Sound monitoring provides the means for continuous observation in environments in which species and populations are notoriously difficult to track, such as rivers and lakes

- Sound can be used to detect and monitor species of interest, help study ecosystem health or the physical habitat, and identify human-generated, noise-related disturbances in aquatic systems

- Further research is needed to determine natural variations in aquatic sounds, find ways to account for background noise, and examine the complex relationship between sound and ecosystem health

- A key next step is systematic cataloging of freshwater sounds; although there are at present more than 2500 scientific publications relating to freshwater bioacoustics, few recordings are available in international sound repositories

\footnotetext{
${ }^{1}$ Australian Rivers Institute, Griffith University, Nathan, Australia *(simon.linke@gmail.com); ${ }^{2}$ Queensland Conservatorium, Griffith University, South Brisbane, Australia; ${ }^{3}$ Sensilab, Monash University, Caulfield East, Australia; ${ }^{4}$ Muséum national d'Histoire naturelle, Institut Systématique, Evolution, Biodiversité ISYEB, Paris, France; ${ }^{5}$ Neuro-PSI CNRS UMR 9197, Université ParisSud, Orsay Cedex, France; Institute of Natural Resource Sciences, Zurich University of Applied Sciences, Wädenswil, Switzerland
}

problems. First, traditional methods of freshwater ecological monitoring can adversely impact the target biota and affect ecosystem health and habitat integrity; second, the act of sampling introduces bias by attracting some species of fish, while inducing flight responses in other taxa; finally, temporal variation is hardly ever considered because this would require mechanical resampling. Consequently, conventional monitoring is often restricted to limited areas, infrequent time intervals, and manual processing of acoustic data.

Passive acoustic monitoring (PAM), which has been used in marine systems for decades, represents a relatively untapped alternative for studying freshwater ecosystems. Acoustic monitoring involves installing one or more hydrophones (underwater microphones) in the habitat of interest to record sound. PAM systems are largely noninvasive, require limited maintenance (aside from periodic battery replacement and data downloads), and allow for continuous long-term observation with temporal resolution determined by automated recording schedules. Moreover, acoustic detection has no discernible negative impacts on biota.

There are, however, a number of specific challenges to operationalizing PAM in freshwater environments: not all biota are soniferous (ie capable of producing or conducting sound), high frequencies are attenuated rapidly in water, sound propagation in shallow water is complex and not fully understood, and very little is known about the particular sounds produced by individual species in most of these environments. Furthermore, acoustic analysis is complicated by varying levels of background noise produced by water turbulence and, in many locations, human activities. In addition, data management and pro- 
cessing time are often problematic. We present suggestions for future research to address these challenges.

\section{Continuous process-based monitoring in freshwater science}

In contrast to sample-based surveys, process-based continuous monitoring is a relatively new approach in ecology. The primary goal is to improve our understanding of the rapid changes occurring in many ecosystems. This technique often uses automated analysis processes to detect these changes. In recent years, several large projects have championed this novel approach (eg the National Ecological Observatory Network [NEON; Denes et al. 2015] and the Remote Environmental Assessment Laboratory [REAL; Kasten et al. 2012] projects). NEON is a long-term program to detect ecological consequences of natural and human-induced environmental changes, and terrestrial sound recorders have been deployed at four NEON sites to conduct acoustic surveys of birds, frogs, and insects. However, continuous monitoring of freshwater environments has yet to be incorporated into any long-term program.

In addition to large-scale projects like NEON and REAL, interest in smaller scale continuous acoustic wildlife monitoring has grown substantially over the past decade (Servick 2014), as researchers in the fields of bioacoustics (animal sounds), and more recently ecoacoustics (the relationship between sound and the environment), have increasingly come to recognize its benefits in both terrestrial and marine settings. Acoustic monitoring in aquatic systems is a noninvasive sampling method, and therefore represents an attractive alternative to conventional sampling techniques. Acoustic signals can provide quantitative information on the biology, ecology, and population status of soniferous aquatic biota through space and time. Such information may include:

- Species presence or absence: for instance, acoustic monitoring has been used in freshwater systems to detect invasive tilapia (Kottege et al. 2015);

- Abundance: to our knowledge, acoustic monitoring has not yet been used in freshwater systems to measure the population abundance of a single species or group of species, but it has been used extensively in marine surveys (eg long-term monitoring of the endangered vaquita porpoise [Phocoena sinus]; Gerrodette et al. 2011);

- Habitat use (eg for feeding or nesting): for example, sediment disturbance by fish during spawning (eg river redhorse, Moxostoma carinatum; Straight et al. 2014);

- Behaviors (eg courtship): acoustic signals during mating behavior have been extensively described (see Amorim et al. [2015] for an overview) and were recently used to estimate fish abundance in a marine fish species, the Gulf corvina (Cynoscion othonopterus) (Rowell et al. 2017); and

- Movement: acoustic monitoring has been used in marine systems to characterize spatiotemporal variation in Atlantic cod (Gadus morhua) via sounds associated with spawning (Hernandez et al. 2013).

We see a role for passive acoustic technology in research on all these aspects of aquatic systems, and especially for processes that require continuous monitoring, such as behavioral traits or movements (eg to retrace precise trajectories).

\section{A history of freshwater bioacoustics}

Descriptions of sonifery in fish extend back 2000 years (as depicted in Aristotle's Historia animalium), and fish behavior and sound production have been active areas of investigation for more than 80 years. The majority of the 2740 articles we recovered via a Google Scholar search using the keywords "+freshwater +bioacoustics" (searched 28 Aug 2017) can be categorized into two broad groups: (1) studies that focused on the mechanisms of biological sound production and behavior and (2) research on the effects of anthropogenic noise on aquatic animals (see next section). The vast literature on fish bioacoustics (see Ladich 2015 for an excellent overview) constitutes a substantial repository of knowledge that could be used in environmental management.

For fish, serious efforts to catalog underwater sounds were first conducted in the 1960s and 1970s, when Fish and Mowbray (1970) systematically cataloged sounds of western North Atlantic fishes, both in situ and in aquaria; however, they focused predominantly on marine fish species. Their final database includes sound recordings of 153 species, all of which are currently available from the Macaulay Library at Cornell University (http://macaulaylibrary.org). These archives contain over 120,000 bird recordings, but only 929 fish recordings, most of which were collected prior to 1980. None of the other major online databases (such as the Berlin Animal Sound Archive) contain a substantial number of freshwater species.

Although some studies published over the past decade have highlighted the potential of PAM, these have almost exclusively focused on marine applications, and particularly marine mammals. Rountree et al. (2006) predicted that "with the advent of new acoustic technologies, passive acoustics will become one of the most important and exciting areas of fisheries research in the next decade". This paradigm shift has not yet occurred, as acoustic monitoring has so far failed to gain traction as a useful research tool in freshwater environments. Despite a minor resurgence in soundscape studies of freshwater environments over the past decade (Anderson et al. 2008; Desjonquères et al. 2015), persistent knowledge gaps continue to inhibit its broader adoption. The following sections will synthesize existing knowledge and identify key research priorities that must be addressed before bioacoustic approaches can be fully integrated into aquatic monitoring protocols and programs. 


\section{Listening to key aquatic groups and processes}

We will limit our discussion to biotic sounds produced by fishes, macroinvertebrates, and the physicochemical environment, as well as anthropogenic noises. Other aquatic groups, such as amphibians, may also call underwater, but they are rarely used as indicators in freshwater ecology.

\section{Fishes}

Fishes are at the top of the food chain in many freshwater ecosystems, and are a taxonomic group of economic, ecological, and cultural importance. Monitoring fish stocks and communities is therefore a key task in the study of freshwater systems. Fine and Parmentier (2015) discussed two main mechanisms of fish sound production. The first consists of swim-bladder vibrations generated by "drumming" muscles (eg species in the family Terapontidae; Figure 1). The second is the use of stridulatory organs, in which sounds are commonly generated via vibrations of the pectoral girdle or by rubbing the pectoral fins against the pectoral girdle (eg in catfish). Fish calls are understood to be species-specific, and within-species call variation is therefore typically lower than between-species call variation (Rollo and Higgs 2008). Species specificity in terms of the dominant frequency (highest-amplitude frequency in a call's spectrum) has been demonstrated for two gobies from the same genus (Pedroso et al. 2013), whereas a study of cichlids found species-specific differences in call pulse rates (Verzijden 2010). These results are encouraging for species-specific monitoring programs, although more research will be needed to determine whether patterns in within-species call variation can be generalized across taxa.

The estimate of 700-800 species of soniferous fish (both freshwater and marine) is likely conservative (Rountree et al. 2006; Luczkovich et al. 2008). For instance, Anderson et al. (2008), in one of the few comprehensive studies that attempted to identify all sounds captured in a freshwater survey, made 164 hours of recordings at two sites, from which only four fish species could be reliably identified. However, the authors described an additional 58 distinct sounds, many of which were likely produced by fish species that could not be identified due to the paucity of knowledge on speciesspecific sound production. In addition, analyses of sonifery usually include only actively emitted sounds and not sounds generated by animals interacting with the environment, such as those associated with sediment disturbance during spawning (Straight et al. 2014).

\section{Macroinvertebrates}

Aquatic macroinvertebrates (aquatic arthropods, mollusks, and worms) are often used as indicators of aquatic ecosystem health in bioassessment and biomonitoring programs (Norris and Thoms 1999), but identification

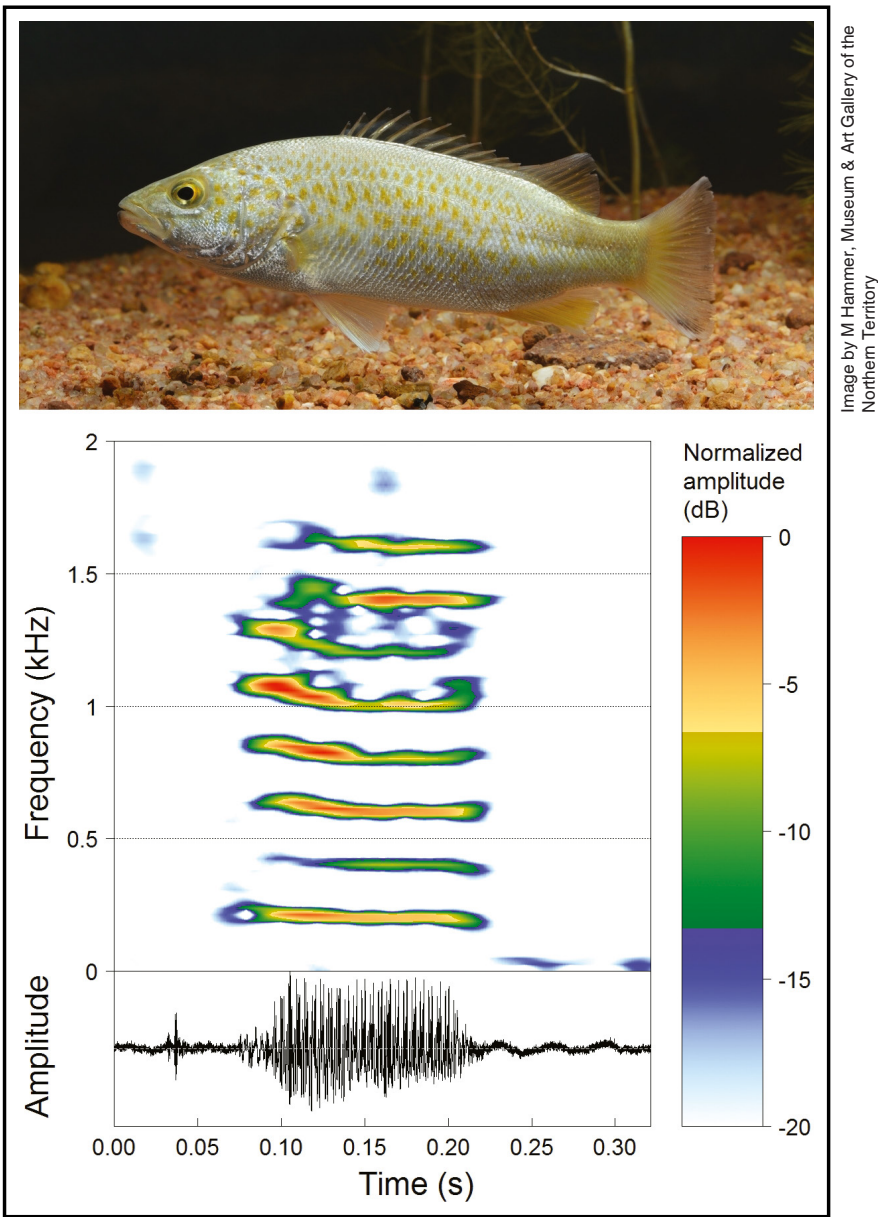

Figure 1. (a) The spangled grunter (Leiopotherapon unicolor) is a sound-producing Australian fish that emits a distinctive grunt by vibrating its swim bladder. (b) A typical grunt has a duration of 100-200 ms and consists of eight parallel frequency bands that move as one, with a varying contour (eg all dipping down and then up simultaneously). This clear acoustic fingerprint can be used for automatic detection (WebAudio File 1).

of samples is time consuming and requires considerable taxonomic expertise. Although ecological community approaches - that is, analyses of sounds emanating from a biological community as a whole - have only rarely been attempted (Desjonquères et al. 2015), numerous studies have described four soniferous aquatic insect orders (Trichoptera, Odonata, Coleoptera, and Hemiptera; see the review by Aiken 1985).

The primary mechanism of sound production among aquatic insects is stridulation, although a few species may produce sounds by other means, such as expulsion of air through the spiracles or flight muscle contraction (Aiken 1985). Soniferous aquatic insects produce a wide diversity of sounds, with dominant frequencies ranging from 200-100 kilohertz $(\mathrm{kHz})$ but concentrated mainly within the 5-6.5 $\mathrm{kHz}$ range (Figure 2; Aiken 1985). Among the known soniferous taxa, the Trichoptera, some Coleoptera, and the Odonata are generally recognized as indicators of healthy freshwater ecosystems, whereas the Hemiptera (Figure 2) are 


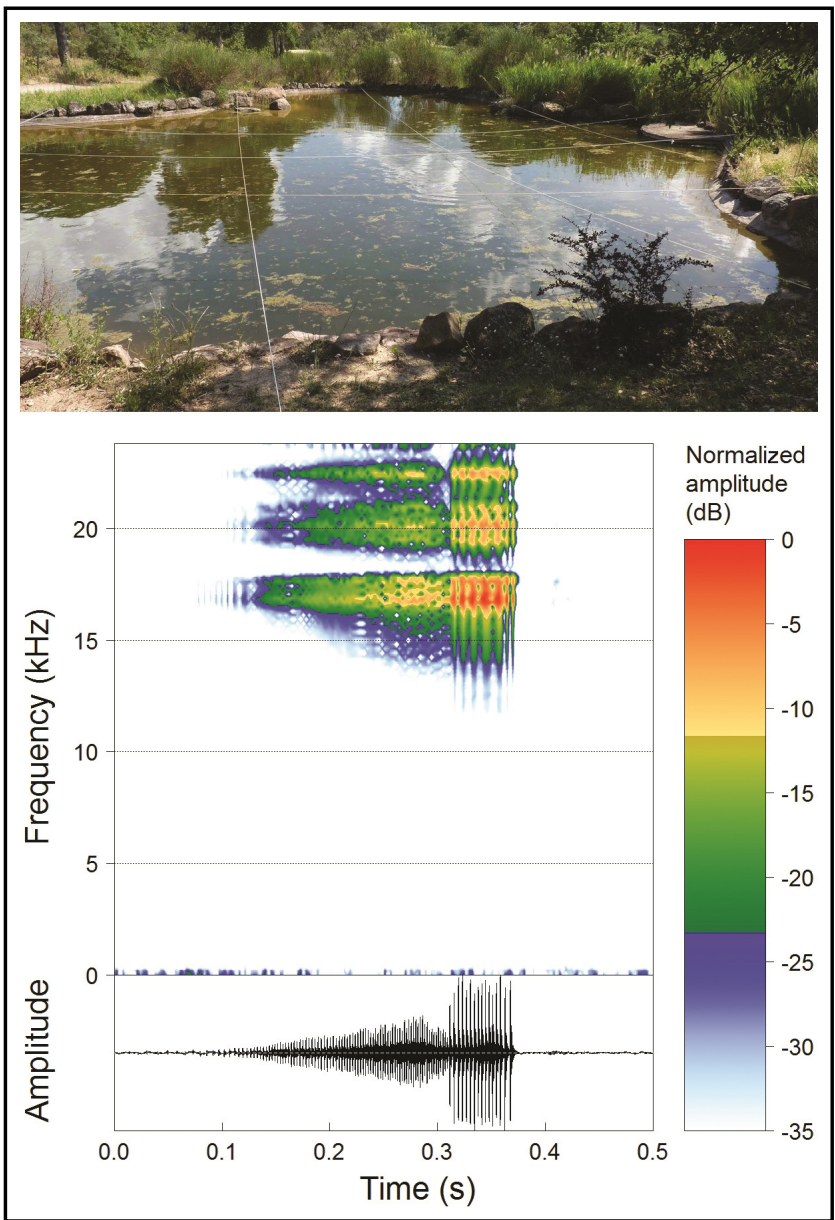

Figure 2. (a) A Mediterranean pond in which the activity of a population of Micronecta was monitored acoustically with an array of 12 hydrophones submerged in the pond using ropes. Micronecta is a genus encompassing several species of pygmy water boatmen that produce distinctive stridulations and that can be used as indicator species in lakes. (b) Micronecta griseola generates a broadband high-pitch sound with a dominant frequency of $\sim 17 \mathrm{kHz}$ and a duration of 0.3 seconds. The sound production of this $2-\mathrm{mm}$ species is very conspicuous and detectable at distances of a few meters (WebAudio File 2).

often pollution tolerant (Norris and Thoms 1999). High species specificity in sound production has been described for some Hemiptera (nine species in one genus; King 1999) and Coloeptera (three species in two genera; Wilson et al. 2015). There is therefore the potential to monitor water quality using the species-specific sounds of these insect taxa, which would complement the recently developed automated processing technologies now commonly used for video identification of underwater insects (Lytle et al. 2010).

\section{Physicochemical processes}

In addition to monitoring sounds emitted by biota, the past decade has also seen an increase in acoustic applications for quantifying physicochemical processes, such as sediment transport and water flow turbulence.

\section{Bedload transport and flow turbulence}

Underwater soundscapes can be used to differentiate among aquatic habitats such as backwaters, pools, runs, and riffles (Amoser and Ladich 2010; Tonolla et al. 2010), and provide a measure of spatial habitat organization (Tonolla et al. 2011). These distinctions are primarily determined by physical processes reflecting important hydraulic processes (such as turbulence) and geomorphic processes (such as bedload transport [sediment transport along a river bed]; WebAudio File 3); specifically, low-frequency sound $(<1 \mathrm{kHz})$ is attributed to flow turbulence, whereas movement of streambed sediment dominates acoustic signals above $1 \mathrm{kHz}$ (Tonolla et al. 2011; Lorang and Tonolla 2014; Geay et al. 2017).

Soundscape analysis could be used for rapid spatial surveying of hydrogeomorphic conditions, and thus to monitor river restoration measures or to characterize the effect of flow release from hydropower plants. Moreover, acoustic signals from streambed particle movements have been used as a non-invasive means of measuring the intensity of bedload transport and distinguishing the size of the material being transported, based on frequency band intensity (Tonolla et al. 2011; Geay et al. 2017). Finally, underwater sounds produced by flow turbulence and bedload transport most likely provide migratory and directional cues for many freshwater organisms (including fish and aquatic invertebrates), given that most aquatic species probably use acoustic cues in their environment for spatial orientation and positioning within and among suitable habitats (Slabbekoorn and Bouton 2008; Fay 2009).

\section{Gas exchange}

Plant respiration and organic matter decomposition emit whistling and ticking sounds when gas bubbles form and are expelled. The sounds produced by oxygen emissions have been used for ecoacoustic monitoring in marine environments (Felisberto et al. 2015) and have also been documented in freshwater environments (WebVideo 1). At the water/air interface, sound has been used to estimate re-aeration - an important component in the estimation of whole-stream metabolism - in streams (Morse et al. 2007).

\section{Threat monitoring}

A growing body of research is concerned with the effect of anthropogenic noise on aquatic ecosystems. Noise can influence aquatic ecosystem health, or be a proxy for other human activities and stressors and can modify behavioral patterns in fish. The groundwork for this was laid in the 1960s, when the response of cutthroat trout (Oncorhynchus clarkii) to natural noise levels in Yellowstone National Park was described by Stober (1969); since then, alterations in the levels of underwater noise have been measured in both lakes 
and rivers (Stober 1969; Amoser and Ladich 2010; Bolgan et al. 2016). At the same time, an increasing number of studies have identified direct impacts of anthropogenic noise on fish behavior (eg Lugli et al. 2003), leading to the conclusion that noise can affect fish in multiple ways: by increasing stress levels, changing dispersal behaviors, and interfering with communication. Anthropogenic noise may also alter predator-prey relationships (Slabbekoorn et al. 2010).

Monitoring of human-caused sounds may be a useful indicator of potentially damaging human activities, so a secondary benefit from acoustic monitoring is threat estimation by proxy. Underwater monitoring arrays could pick up anthropogenic influences that do not act directly on biota but are an indicator of threats, such as boat, vehicle, or even airplane noise, and proximity to roads or bridges (Kuehne et al. 2013).

\section{Continuous ecoacoustic monitoring in freshwater environments}

Working toward a system that can be used to monitor changes in freshwater ecosystems, we propose combining acoustic monitoring of the four elements discussed above (fishes, macroinvertebrates, physicochemical processes, and threats). Until now, continuous long-term monitoring has only been feasible for physical elements of a river, for example by means of flow gauges or probes to measure water temperature and/or water chemistry. A system that tracks soniferous fishes, macroinvertebrates, and ecosystem processes simultaneously could help to monitor both natural variation and anthropogenic changes in near real time (Figure 3). Continuous recording could also facilitate quantification of natural cyclic phenomena (ie diurnal, lunar, seasonal, and annual variation in environmental and ecological properties), which would allow natural variation to be accounted for when diagnosing anthropogenic changes. Such holistic acoustic monitoring systems have been suggested for terrestrial and marine environments by several authors (eg Kasten et al. 2012; Towsey et al. 2012).

Research on automated acoustic detection of various species has been expanding in recent years (eg Stowell and Plumbley [2014] classifying bird sounds; Colonna et al. [2015] monitoring frogs). However, in addition to a study that monitored sediment disturbance associated with spawning of a large, iconic fish species from the family Catostomidae in the southern US (Straight et al.
2014), only a single study has attempted to automatically detect calls of a freshwater fish species (that of Kottege et al. [2015], who monitored spotted tilapia [Pelmatolapia mariae], an invasive fish in Australia, by means of their calls). Automated detection algorithms typically require some "training data" of known calls of the desired type to match against, but this presents a major challenge in many freshwater environments, because little is currently known about the structure and variety of sounds made by target biota in most aquatic systems. We believe that a thorough study of local environmental and speciesspecific sounds will be a prerequisite for any automated monitoring program.

Another challenge for automated monitoring is data storage. Despite exponential increases in affordable storage capacity over the past several decades, data storage remains problematic, particularly for remote portable recording stations (Aide et al. 2013). Data management has been an associated issue with temporally continuous PAM requiring either on-site data storage or limited samples (typically 5 minutes every hour). On-site storage limits the duration of recording without travelling to a site and downloading data, and is prone to water damage or impairment due to other, unanticipated events. The availability of inexpensive and energy-efficient microprocessors and widespread high-speed wireless communication networks offers potential solutions to these problems. By using low-cost microprocessors, audio processing for real-time detection can be run in situ, with high-bandwidth audio stored or transmitted only in cases of detection events (Kasten et al. 2012). Moreover, the reduced energy demand and consumption 
of these devices increases the feasibility of long-term remote monitoring being powered by local solar arrays.

\section{Key research questions to be addressed}

Because the science of ecoacoustic monitoring in freshwater systems is still in its infancy, several key research questions must be addressed before a general approach to freshwater monitoring can be developed. Although some of these issues apply to many different kinds of ecosystems (eg the need to characterize spatiotemporal dynamics of sounds and optimize detection performance), freshwater environments often present additional and unique challenges.

\section{Identification and cataloging of species-specific sounds}

A comprehensive worldwide catalog of single-species calls and incidental sounds would greatly aid the development and implementation of monitoring schemes by acting as a reference library and clarifying the level of specificity of species' calls. A number of studies exist that describe the sounds emitted by fishes and macroinvertebrates, as well as noises in various freshwater contexts (see above), but this information is fragmented across the spectrum of acoustic, biological, and ecological research. Although few multi-taxon surveys of freshwater systems have been conducted (eg Anderson et al. 2008; Desjonquères et al. 2015), there is extensive research on the behavioral ecology of fishes (Ladich 2015) and the anatomy of sound production (Fine and Parmentier 2015). Collecting and cataloging the sounds of species associated with these single-taxon studies - as well as some of the multi-taxon surveys - would represent a major step toward practical operationalization.

Recordings of underwater sounds are kept in repositories such as the Macaulay Library sound archive at Cornell University, but the majority of these recordings are decades old, unlike the more recently published literature, in which freshwater acoustics research is actively being conducted across many spatial domains and with many different objectives. For passive acoustics to play a major role in freshwater science, this information needs to be assembled in a single repository, one where cataloged sounds are linked to correlating metadata (Roch et al. 2013); Bird-DB is an example of such a database, albeit for terrestrial bioacoustics. If a similar repository were constructed for freshwater organisms, it could then be linked to environmental and biodiversity data available from the Global Biodiversity Information Facility (Flemons et al. 2007), the Freshwater Information Platform (www.freshwaterplatform.eu), or similar repositories, to enable more thorough syntheses and analyses. This could potentially speed identification of unknown sounds in aquatic systems, facilitating development of pathways to ecoacoustic monitoring approaches.

\section{Developing appropriate sampling methodologies and statistical techniques}

As with other types of biological assessments in water bodies, ecoacoustic approaches will need to account for spatial and temporal variation in acoustic soundscapes, and monitoring regimes will have to be tailored to account for that variation.

Spatial variation in freshwater soundscapes is still largely unexplored apart from two studies. Both Desjonquères et al. (2015) in ponds and Tonolla et al. (2011) in rivers found that between-site variation in soundscapes was greater than within-site patchiness - an encouraging preliminary result. However, generalizations will only be possible once comprehensive studies assessing sound propagation, as well as patchiness in freshwater systems, have been conducted, thereby laying the foundation for adequate spatial sampling designs in freshwater systems.

All bioacoustic monitoring systems grapple with trade-offs between data volume and recording adequacy: how many hours of recording need to be analyzed to detect trends in ecosystem change. A first, thorough examination of temporal sampling for terrestrial ecoacoustic monitoring concluded that, although there is no magic-bullet solution, diurnal sampling could be optimized so that different habitats are assessed reasonably comprehensively (Pieretti et al. 2015). There will likely be the need for calibration depending on the ecosystem, especially as little research has been conducted on temporal patterns in sound-producing activities among freshwater organisms. However, the results of an unpublished pilot study conducted in our lab suggested that 5 -second samples taken every 20 minutes over 6 days was enough to capture a fairly comprehensive variety of sound events, although 24-hour sampling was required to capture all sounds.

Temporal acoustic data are often analyzed in the form of acoustic indices - a summary of the raw sound data analogous to richness, diversity, or evenness indices in community ecology. Like their counterparts, these indices require appropriate statistical methods for discriminating statistically significant differences between sites and over time. Methods borrowed from time-series analyses will be particularly pertinent in order to account for serial correlation in acoustic measurements. Indeed, this has been identified as an important issue in ecoacoustics generally (Farina and Gage 2017).

\section{Improving location-specific automatic detection}

The performance of an automatic detection system is usually evaluated by computing outcome metrics, such as sensitivity, specificity, and precision (Colonna et al. 2015). These metrics depend on the number of falsepositive or false-negative detections when comparing the outputs of automatic and manual detections. As with any automatic detection program, these metrics might be affected by non-biological background noise, such as that made by flowing water, rainfall, or boat engines 
(Farina and Gage 2017). Moreover, detection of a target sound can also be made difficult by the co-occurrence of other competing biological sounds. Therefore, environments with high background noise levels, due to anthropogenic noise, geophonic sounds (detected in rock, soil, or ice), or other co-occurring species, require algorithmic optimization to ensure reliable detection of the sound of interest (Towsey et al. 2012). These technical challenges are not unique to freshwater environments, but the acoustic properties of, for example, shallow streams mean that these challenges require research specific to the medium; the acoustic effects of wind and rainfall on underwater soundscapes differ from those in terrestrial soundscapes. In addition, standard acoustic indices that account for background noise (Pieretti and Farina 2013) will need to be developed for freshwater systems.

\section{Links between sounds and ecosystem health}

A recent trend in environmental acoustics is the development of holistic acoustic approaches, in which environmental acoustic recordings are analyzed as a whole, as opposed to trying to isolate individual biotic sounds, as has been typical of bioacoustic research in the past (for an overview of the most commonly used indices, see Sueur et al. 2014). Various acoustic indices have been related to non-acoustic environmental indicators. Acoustic diversity, richness, or complexity indices are proven proxies for biodiversity (Sueur et al. 2014) and habitat heterogeneity (Tonolla et al. 2011).

In freshwater environments, however, the relationship between acoustic richness and ecosystem health is neither straightforward nor universal; richer soundscapes may indicate greater biodiversity and less impacted habitat in some contexts, whereas in others the opposite may be true. For example, soniferous invertebrate abundance underwater can be an indicator of both good and poor ecosystem health. Furthermore, the abovementioned temporal variation and spatial microvariation in underwater acoustics (Desjonquères et al. 2015) complicates analysis of any potential relationships between acoustic indices and ecosystem health. For instance, Pieretti and Farina (2013) reported a correlation between fish richness and an index of acoustic complexity, but Staaterman et al. (2014) suggested that variation in acoustic complexity could mainly be attributed to individual organisms. Gage and Axel (2014) also highlighted the notion that index choice is neither simple nor clear-cut, and made the case for filtering different frequency bands to increase specificity. This underscores the critical need for further research in this field in order to establish appropriate metrics and robust recording protocols.

\section{Conclusion}

A wealth of information about freshwater ecosystems can be obtained through acoustic recordings of multiple trophic levels of biota and the surrounding physicochemical environment (Figure 3). Acoustic monitoring offers several advantages over existing techniques: it is non-invasive, mitigates observer effects, and affords high spatial and temporal resolution; it also potentially can be implemented for large-scale, long-term projects at reasonable cost.

We believe that whole-ecosystem acoustic monitoring of aquatic ecosystems will be feasible within the next decade, and indeed terrestrial programs are already proliferating. However, several key challenges will have to be overcome to design an operational framework in freshwater environments, as outlined in the above sections.

We view this paper as a call to action for freshwater ecoacousticians, as well as the wider freshwater research community, to share resources and contribute to a collective knowledge base, which could transform freshwater ecoacoustics into an operational discipline for wholeecosystem monitoring beyond single-species studies over the medium term.

\section{Acknowledgements}

SL was supported by ARC DECRA DE130100565; CD was supported by an ENS PhD grant. We thank F Vaillant for providing us with the video of plant sound production. We would also like to thank P Roe, S Fuller, M Towsey, M Ferroudj, and the QUT bioacoustics group; M Maggs and M Calder from Frontier Labs; and J Wood from the Goulburn-Broken CMA for fruitful discussions and exciting collaborations; and the Ewamian Aboriginal Corporation, on whose land SL, TG, and CK conducted most of the research, and where the final draft of this manuscript was written. Extensive comments by J Olden greatly improved the manuscript.

\section{References}

Aide TM, Corrada-Bravo C, Campos-Cerqueira M, et al. 2013. Real-time bioacoustics monitoring and automated species identification. PeerJ 1: e103.

Aiken RB. 1985. Sound production by aquatic insects. Biol Rev 60: $163-211$

Amorim MCP, Vasconcelos RO, and Fonseca PJ. 2015. Fish sounds and mate choice. In: Ladich F (Ed). Sound communication in fishes. Vienna, Austria: Springer.

Amoser S and Ladich F. 2010. Year-round variability of ambient noise in temperate freshwater habitats and its implications for fishes. Aquat Sci 72: 371-78.

Anderson KA, Rountree RA, and Juanes F. 2008. Soniferous fishes in the Hudson River. T Am Fish Soc 137: 616-26.

Bolgan M, Chorazyczewska E, Winfield IJ, et al. 2016. First observations of anthropogenic underwater noise in a large multi-use lake. J Limnol 75: 644-51.

Colonna JG, Cristo M, Salvatierra Júnior M, and Nakamura EF. 2015. An incremental technique for real-time bioacoustic signal segmentation. Expert Syst Appl 42: 7367-74.

Denes SL, Parks SE, Matthews L, et al. 2015. Continental scale acoustic monitoring program: one year of data. J Acoust Soc Am 137: 2220 .

Desjonquères C, Rybak F, Depraetere M, et al. 2015. First description of underwater acoustic diversity in three temperate ponds. PeerJ 3: e1393. 
Farina A and Gage S. 2017. Ecoacoustics: a new science. In: Farina A and Gage S (Eds). Ecoacoustics: the ecological role of sounds. Hoboken, NJ: John Wiley \& Sons.

Fay R. 2009. Soundscapes and the sense of hearing of fishes. Integr Zool 4: 26-32.

Felisberto P, Jesus SM, Zabel F, et al. 2015. Acoustic monitoring of $\mathrm{O}_{2}$ production of a seagrass meadow. J Exp Mar Biol Ecol 464: $75-87$.

Fine ML and Parmentier E. 2015. Mechanisms of fish sound production. In: Ladich F (Ed). Sound communication in fishes. Vienna, Austria: Springer.

Fish MP and Mowbray WH. 1970. Sounds of western North Atlantic fishes. A reference file of biological underwater sounds. Baltimore, MD: Johns Hopkins Press.

Flemons P, Guralnick R, Krieger J, et al. 2007. A web-based GIS tool for exploring the world's biodiversity: The Global Biodiversity Information Facility Mapping and Analysis Portal Application (GBIF-MAPA). Ecol Inform 2: 49-60.

Gage SH and Axel AC. 2014. Visualization of temporal change in soundscape power of a Michigan lake habitat over a 4-year period. Ecol Inform 21: 100-09.

Geay T, Belleudy P, Gervaise C, et al. 2017. Passive acoustic monitoring of bed load discharge in a large gravel bed river. J Geophys Res-Earth 122: 528-45.

Gerrodette T, Taylor BL, Swift R, et al. 2011. A combined visual and acoustic estimate of 2008 abundance, and change in abundance since 1997, for the vaquita, Phocoena sinus. Mar Mammal Sci 27: E79-100.

Hernandez KM, Risch D, Cholewiak DM, et al. 2013. Acoustic monitoring of Atlantic cod (Gadus morhua) in Massachusetts Bay: implications for management and conservation. ICES J Mar Sci 70: 628-35.

Kasten EP, Gage SH, Fox J, and Joo W. 2012. The remote environmental assessment laboratory's acoustic library: an archive for studying soundscape ecology. Ecol Inform 12: 50-67.

King IM. 1999. Species-specific sounds in water bugs of the genus Micronecta. Part 1. Sound analysis. Bioacoustics 9: 297-323.

Kottege N, Jurdak R, Kroon F, and Jones D. 2015. Automated detection of broadband clicks of freshwater fish using spectrotemporal features. J Acoust Soc Am 137: 2502-11.

Kuehne L, Padgham B, and Olden J. 2013. The soundscapes of lakes across an urbanization gradient. PLoS ONE 8: e55661.

Ladich F (Ed). 2015. Sound communication in fishes. Vienna, Austria: Springer.

Lorang MS and Tonolla D. 2014. Combining active and passive hydroacoustic techniques during flood events for rapid spatial mapping of bedload transport patterns in gravel-bed rivers. Fund Appl Limnol 184: 231-46.

Luczkovich JJ, Mann DA, and Rountree RA. 2008. Passive acoustics as a tool in fisheries science. T Am Fish Soc 137: 533-41.

Lugli M, Yan H, and Fine M. 2003. Acoustic communication in two freshwater gobies: the relationship between ambient noise, hearing thresholds and sound spectrum. J Comp Physiol A 189: 309-20.

Lytle DA, Martínez-Muñoz G, Zhang W, et al. 2010. Automated processing and identification of benthic invertebrate samples. J N Am Benthol Soc 29: 867-74.

Morse N, Bowden WB, Hackman A, et al. 2007. Using sound pressure to estimate reaeration in streams. J N Am Benthol Soc 26: 28-37.

Norris RH and Thoms MC. 1999. What is river health? Freshwater Biol 41: 197-209.

Pedroso SS, Barber I, Svensson O, et al. 2013. Courtship sounds advertise species identity and male quality in sympatric Pomatoschistus spp gobies. PLoS ONE 8: e64620.
Pieretti N and Farina A. 2013. Application of a recently introduced index for acoustic complexity to an avian soundscape with traffic noise. J Acoust Soc Am 134: 891-900.

Pieretti N, Duarte MHL, Sousa-Lima RS, et al. 2015. Determining temporal sampling schemes for passive acoustic studies in different tropical ecosystems. Trop Conserv Sci 8: 215-34.

Roch MA, Baumann-Pickering S, Hwang D, et al. 2013. Tethys: a workbench for bioacoustic measurements and environmental data. J Acoust Soc Am 134: 4176.

Rollo A and Higgs D. 2008. Differential acoustic response specificity and directionality in the round goby, Neogobius melanostomus. Anim Behav 75: 1903-12.

Rountree RA, Gilmore RG, Goudey CA, et al. 2006. Listening to fish: applications of passive acoustics to fisheries science. Fisheries 31: 433-46.

Rowell TJ, Demer DA, Aburto-Oropeza O, et al. 2017. Estimating fish abundance at spawning aggregations from courtship sound levels. Sci Rep-UK 7: 3340.

Servick K. 2014. Eavesdropping on ecosystems. Science 343: 834-37.

Slabbekoorn H and Bouton N. 2008. Soundscape orientation: a new field in need of sound investigation. Anim Behav 76: e5-8.

Slabbekoorn H, Bouton N, van Opzeeland I, et al. 2010. A noisy spring: the impact of globally rising underwater sound levels on fish. Trends Ecol Evol 25: 419-27.

Staaterman E, Paris CB, DeFerrari HA, et al. 2014. Celestial patterns in marine soundscapes. Mar Ecol-Prog Ser 508: $17-32$.

Stober QJ. 1969. Underwater noise spectra, fish sounds and response to low frequencies of cutthroat trout (Salmo clarki) with reference to orientation and homing in Yellowstone Lake. T Am Fish Soc 98: 652-63.

Stowell D and Plumbley MD. 2014. Automatic large-scale classification of bird sounds is strongly improved by unsupervised feature learning. PeerJ 2: e488.

Straight CA, Freeman BJ, and Freeman MC. 2014. Passive acoustic monitoring to detect spawning in large-bodied catostomids. T Am Fish Soc 143: 595-605.

Sueur J, Farina A, Gasc A, et al. 2014. Acoustic indices for biodiversity assessment and landscape investigation. Acta Acust United Ac 100: 772-81.

Tonolla D, Acuña V, Lorang MS, et al. 2010. A field-based investigation to examine underwater soundscapes of five common river habitats. Hydrol Process 24: 3146-56.

Tonolla D, Lorang MS, Heutschi K, et al. 2011. Characterization of spatial heterogeneity in underwater soundscapes at the river segment scale. Limnol Oceanogr 56: 2319-33.

Towsey M, Planitz B, Nantes A, et al. 2012. A toolbox for animal call recognition. Bioacoustics 21: 107-25.

Verzijden MN. 2010. Sounds of male Lake Victoria cichlids vary within and between species and affect female mate preferences. Behav Ecol 21: 548-55.

Wilson N, Flinn MB, West B, and Hereford J. 2015. Identification of sound-producing hydrophilid beetles (Coleoptera: Hydrophilidae) in underwater recordings using digital signal processing. Coleopts Bull 69: 305-15.

\section{Supporting Information}

Additional, web-only material may be found in the online version of this article at http://onlinelibrary. wiley.com/doi/10.1002/fee.1779/suppinfo 